A Review of the Collective Interviewing Approach to Detecting Deception in Pairs

\author{
Zarah Vernham $^{1}$
}

Aldert Vrij

University of Portsmouth

\footnotetext{
${ }^{1}$ Correspondence concerning this article should be addressed to: Zarah Vernham, University of Portsmouth, Psychology Department, King Henry Building, King Henry 1 Street, Portsmouth, PO1 2DY, UK, or via e-mail: zarah.vernham@port.ac.uk.
} 


\begin{abstract}
Collective interviewing - the interviewing of multiple suspects simultaneously - has been neglected within the deception detection literature, yet it has the potential to have theoretical and practical implications for professionals involved in citizen security. The current review recaps the importance of lie detection and when collective interviewing can be used, before summarising the collective interviewing deception studies published to date. The published studies show that a lack of interactive and communicative cues, such as posing questions to one another, correcting one another, interrupting one another, finishing each other's sentences, and looking at one another, are significant indicators of deceit. The review highlights that theories about memory and group dynamics are crucial to understanding the deception occurring within groups, and therefore should be the focus of future collective interviewing deception studies. Additionally, some comparisons are made between individual and collective interviewing with the take home message that collective interviewing should not replace individual interviewing, but that both types of interviewing should be used, perhaps sometimes in conjunction with one another.
\end{abstract}

Keywords: Deception; Collective Interviewing; Cognitive Load; Memory; Groups 


\section{A Review of the Collective Interviewing Approach to Detecting Deception in Pairs}

\section{Importance of studying deception detection}

An understanding of deception (a deliberate attempt to mislead others; DePaulo et al., 2003) and its detection is particularly important in criminal, intelligence and security investigations, as investigators need appropriate fact-finding interview styles to be able to differentiate truth-telling from lying individuals. Accuracy rates for practitioner lie catchers in empirical research are generally low, ranging from $45 \%$ to $60 \%$ (Bond \& DePaulo, 2006; Vrij, 2008a), and such low accuracy rates can be expected given the challenging nature of lie detection. For example, cues to deceit are typically subtle, and liars frequently use countermeasures to appear credible. Also, professional lie catchers make common errors such as examining the wrong cues or placing too much emphasis on nonverbal cues (see Vrij, Granhag \& Porter, 2010 for a review of the challenges and errors associated with detecting deceit).

Through realising that cues are subtle, researchers started to develop interview protocols that can assist professionals with the aim of eliciting and magnifying the verbal and nonverbal cues to deception by focussing on the different psychological mental states of truthtellers and liars (Vrij \& Granhag, 2012). The two most extensively examined approaches to date are the 'Strategic Use of Evidence' (SUE) technique and the cognitive lie detection approach (see Granhag \& Hartwig, 2015; Hartwig, Granhag \& Luke, 2014; Vrij, 2015; Vrij, Fisher, Blank, Leal \& Mann, in press; Vrij, Leal, Mann, Vernham \& Brankaert, 2015, for overviews of this research). In this article, we review one of these new interviewing protocols belonging to the cognitive lie detection approach: Collective interviewing, which is the interviewing of multiple suspects simultaneously. 


\section{Collective interviewing}

Deception detection research has primarily focused on the interviewing of single suspects despite the fact that crimes, or other forms of wrongdoings, are frequently committed by multiple individuals ( $\mathrm{M}^{\mathrm{c}}$ Gloin \& Piquero, 2009; Soufan, 2011; Van Mastrigt \& Farrington, 2009). For example, police detectives typically separate suspects as soon as possible prior to interrogation to reduce opportunity for planning of responses, and to increase the suspects' stress and anxiety (Kassin \& Gudjonsson, 2004). To reflect this practice, in the few studies that have considered groups of truth-tellers and groups of liars (always pairs), the group members were interviewed individually (e.g. Granhag, Strömwall \& Jonsson, 2003; Strömwall, Granhag \& Jonsson, 2003; Vrij et al., 2009). Consequently, investigators are required to manage numerous statements from several suspects at any one time.

When lie catchers have access to numerous statements, they tend to focus on verbal consistency between these statements (Strömwall et al., 2003). Although verbal cues are more diagnostic of deceit than nonverbal cues (Vrij, 2008b), research has identified that purely comparing verbal statements from multiple individuals in a group, in terms of consistency, is not effective. Statements from lying groups, although more vague, appear as consistent as statements from truth-telling groups because liars plan and rehearse a cover-story and stick to that rehearsed story (Granhag et al., 2003; Strömwall et al., 2003; Vrij, Mann, Leal \& Granhag, 2010). In contrast, truth-tellers do not pre-plan their responses and instead rely on memory which is inherently reconstructive in nature (Bartlett, 1932; Granhag \& Strömwall, 1999). Their statements may in fact be less consistent than those obtained from liars due to memory distortions such as omission errors (the leaving out of information) and commission errors (the adding in of information). Hence, it is clear that lie catchers need to be cautious when interviewing multiple suspects individually and interpreting consistent statements as truthful and inconsistent statements as mendacious. 
There are several field settings in which collective interviewing would be more suited than interviewing individuals separately, for example, during police stop and searches, at road border controls where cars containing several people are checked, at security checkpoints (e.g., airports), during immigration interviews, or during house to house enquiries. These settings often tend to be intelligence-gathering or security contexts where the focus is on preventing actions that may cause harm, rather than catching groups of individuals who have already caused harm. In such settings, it would be more timely and convenient to interview the group members simultaneously, particularly if there is only one interviewer available.

Although collective interviewing is a new line of research within the deception detection literature, it is already used in practice. For example, in the UK, immigration officers use collective interviewing at one potential stage, when attempting to uncover sham marriages (marriages of convenience whereby the marriage is not genuine; Home Office, 2013). Also in the UK, police detectives question people in groups when making house to house enquiries. In Canada, customs officers carry out collective interviews at airports because groups are deemed to have 'similar issues'; thus if only one person in the group is examined, this could result in a wasted effort or a missed opportunity (A. Leach, Canadian former customs officer, personal communication, November $12^{\text {th }} 2013$ ).

Collective interviewing provides a different insight into deception compared with interviewing individuals separately. Collective interviewing will determine deception at an individual level as well as at a social level, and the latter enables new cues to deceit to be identified from the group that cannot be explored in individuals, e.g., cues stemming from individuals communicating and interacting with one another. Consequently, the approach will enable new interview techniques to be explored that allows for deception detection when two or more individuals are interviewed together about the same event. Additionally, group interviewing compliments memory research, which focuses on collaborative learning and 
remembering, as well as research into group processes, which focuses on group formation and leadership. Hence, a collective approach allows for alternative theories and concepts to be applied to deception that cannot be applied when interviewing only individuals, such as transactive memory (Wegner, 1987), collective memory (Barnier \& Sutton, 2008), dominance (Rogers-Millar \& Millar, 1979), and group dynamics (Arrow, McGrath \& Berdahl, 2000). To date, all collective interviewing deception studies have been based on memory theory, with none of them considering group dynamics. We therefore discuss the group dynamics literature relevant for collective interviewing in the 'future research' section.

\section{Theoretical underpinnings behind a collective approach: Memory processes}

It is widely acknowledged that memory plays an important role in deception (Sporer \& Schwandt, 2006; Verschuere, Ben-Shakhar \& Meijer, 2011; Walczyk, Igou, Dixon \& Tcholakian, 2013), and that the act of remembering is, at least in part, influenced by social dynamics (Halbwachs, 1992; Hirst \& Rajaram, 2014). Previously, memory literature has focused on individual memory, ignoring the significance of collective memory whereby groups of individuals share, remember, and recall memories together (also referred to as social memory or collaborative remembering). However, the benefits of collective memory are now being emphasised. For example, Pociask and Rajaram (2014) found that participants were more likely to solve assigned problems associated with material they had studied if they were working collaboratively compared to individually. Additionally, there are three cognitive processes that aid collaborative recall: Re-exposure (hearing another group member recall information that they themselves had forgotten), cross-cueing (hearing another group member recall information that reminds them of additional information), and error-pruning (where feedback from other members of the group create discussions that make people realise their recall errors) (Blumen and Stern, 2011; Rajaram, 2011; Ross, Blatz \& Schryer, 2008). These cognitive processes cannot occur when recall occurs individually. 
Collective interviewing coincides with this memory research which is increasingly focusing on collective memory and collaborative recall. Given that research suggests that group collaboration can aid memory through re-exposure, cross-cueing, and error-pruning, it is not surprising that deception studies using collective interviewing have found that communicative and interactive cues between group members occur more frequently in truthtellers who are actually recalling a joint experienced event compared to liars who are fabricating an event (e.g., Driskell, Salas \& Driskell, 2012; Vernham, Vrij, Leal, Mann \& Hillman, 2014; Vrij et al., 2012). As our understanding of collective memory improves so will our understanding of how groups recall information together when being truthful. That is, if more is known about how truthful group members share and recall information together, more can be learnt about how they differ from group members who are fabricating shared events and attempting to deceive the recipient(s). Consequently, investigators can employ specific interview strategies that aid the remembering of truth-tellers but disrupt the recall of information from liars.

The theory of Transactive Memory is concerned with how groups (and individuals) process and structure information with regard to past events. The theory postulates that people who are in a close relationship share remembering (e.g., through discussing the event to reach a shared understanding of that event) and know each other's memory expertise (i.e. each person knows what s/he is to remember as well as what the other person in the pair is to remember; Hollingshead \& Brandon, 2003). This leads to a transactive memory system referring to the interactions occurring within the individuals of the group and the processes developed to update shared memories - that is greater than the total of both the individual memories (Wegner, 1987; Wegner, Erber \& Raymond, 1991; Wegner, Giuliano \& Hertel, 1985). 
A transactive memory system is active at all three stages of memory formation and recall; (1) when information is encoded regarding a shared experience, responsibility for remembering the information is divided and shared between the members of the pair (e.g., through instructions, such as "Zagor, remember this phone number", or through negotiation, such as "Don't you think you are better at remembering this sort of information than I am?") (Hollingshead \& Brandon, 2003); (2) when information is stored, each individual within the pair has remembering responsibilities, knowing what their role is, what they are to remember, and what information their partner has access to (e.g., if you know your partner is good at remembering everything about cars, then you know you can ask him/her anything about the cars you rented whilst on your holidays abroad together) (Wegner et al., 1991); and (3) retrieval of information is social and interactive as the individuals within the pair communicate considerably with one another to retrieve as much information as possible (e.g., by posing questions to one another). Hollingshead (1998) refers to the transaction memory search whereby group members who have actually experienced a past shared event make automatic use of their transactive memory system to increase recall. Their communication with one another and the discussion of incoming information enhances their individual recollections. Hence, it is during this retrieval stage that deception researchers can measure communicative and interactive cues indicative of those that are telling the truth (e.g., posing questions to one another, reminding one another of further details, correcting each other, and adding information to each other's accounts) (Driskell et al., 2012; Jundi, Vrij, Hope, Mann \& Hillman, 2013; Vernham, Vrij, Leal et al., 2014; Vrij et al., 2012).

Pairs or groups of individuals who are (partially) inventing shared events will need to deceive investigators. For lying groups to be able to do this, they need to illustrate the same pattern of responses as the truth-telling groups. This will be difficult to do without a shared memory system for encoding, storing and retrieving information. Indeed, deceptive 
communication is characterised by the absence of social and interactive behaviours (Driskell et al., 2012; Jundi, Vrij, Hope et al., 2013; Jundi, Vrij, Mann et al., 2013; Vernham, Vrij, Leal et al., 2014). Instead, lying pairs rely on their individual processes, which means that each member needs to rely on their individual cognitive ability to create a story that makes sense and matches with what the other individual in their pair has said (Hintz, 1990). Consequently, they exhibit fewer interactions (Driskell et al., 2012; Vrij et al., 2012), and, due to the misconceptions held by people with regard to which cues imply deceit, they will actually avoid behaviours displayed by truth-tellers, such as correcting and interrupting one another and posing questions to one another, through fear that these behaviours will make them appear guilty (Vrij, 2008a). Truth-tellers will not avoid such behaviours because they believe the truth will shine through ('illusion of transparency'; Gilovich, Savitsky \& Medvec, 1998).

To summarise, two people recalling a jointly experienced event will do so in a different manner than two people who are attempting to recall a fabricated event. Consequently, an understanding of the ways in which groups recall shared events together is vital to enhancing our understanding of joint memory recall and subsequently group deceit. That is, not only should the focus be on the information that is reported, but also on how group members interact with each other when reporting that information.

\section{Collective interviewing studies: What do we know so far?}

To date, seven studies have been published that have applied a collective interviewing approach to the detection of deception (see Table 1 for an overview of these studies and findings). These studies examined deception in different contexts (see Table 1) and examined different verbal and nonverbal communication cues (see Table 1). In one study, a novel interview procedure was introduced - forced turn-taking - and when this was implemented, liars found it more challenging to cope with than truth-tellers. 
Driskell et al. (2012) used 26 pairs of police officers or fire-fighters who knew each other well because they had previously worked together as partners in real life. Pairs of truthtellers were asked to describe a recent event that they had jointly participated in. Pairs of liars were instructed to fabricate a story that did not actually take place, but that involved them doing something together. All participants had a moment to decide what event they would discuss. The theory of transactive memory was applied and it was found that pairs of truthtellers illustrated more synchrony in social behaviours (i.e. co-occurrence of behaviours, e.g., mutual eye gaze) and exhibited more interactions (e.g., verbal transitions whereby one person's speech immediately follows the other person's speech) than pairs of liars. This study used real-life events that were relevant to the pairs of participants; hence increasing ecological validity. However, in this study, ground truth could not be established, which makes it difficult to measure whether the liars definitely lied and the truth-tellers definitely told the truth.

In Vrij et al. (2012), 21 pairs of truth-tellers went out for lunch in a nearby restaurant, whereas 22 pairs of liars were asked to steal $£ 10$ from an office. On returning to the laboratory, truth-tellers were informed about the stolen money and told that they were going to be interviewed about their whereabouts at the time the money was taken, and that they should tell the truth about their time in the restaurant. In contrast, liars were told that they were going to be interviewed about their activities but that they were not to admit to having taken the money. Instead, they were instructed to prepare an alibi about having gone to a nearby restaurant together for lunch. All pairs were given as much time as they needed to prepare for the interview and were not informed that they would be interviewed together. It was found that pairs of truth-tellers interrupted and corrected each other more than pairs of liars, as well as adding more information to each other's accounts in comparison to pairs of liars. 
Jundi, Vrij, Mann, et al. (2013) used Vrij et al.'s (2012) data-set, but examined participants' eye contact. They found that pairs of liars tended to make more eye contact with the interviewer than pairs of truth-tellers, whereas pairs of truth-tellers looked more at each other than pairs of liars. The studies by Vrij et al. (2012) and Jundi, Vrij, Mann, et al. (2013) used artificial tasks in which ground truth was established. However, there was a lack of ecological validity.

In Jundi, Vrij, Hope et al. (2013), 24 pairs of truth-tellers completed a mission whereby they undertook a 'Visit a Park' campaign, whilst 23 pairs of liars completed a mission whereby they undertook an 'Animal Rights' campaign. The task for all pairs was to convince an interviewer that they had completed the 'Visit a Park' campaign. All pairs were given as much time as they required to prepare for the interview and were not informed whether they would be interviewed separately or together. In the interview, the pairs were asked to illustrate on a timeline how long each aspect of their campaign had taken. They were instructed to work together to indicate exactly what they had done and at what times. It was found that, compared to lying pairs, truth-telling pairs posed more questions to one another whilst completing the timeline task, which provides support for the theory of transactive memory. The authors demonstrated that $71 \%$ of truth-tellers and $87 \%$ of liars could be classified correctly on the basis of this task. However, these accuracy rates need to be interpreted with caution because they were based on group means rather than on predetermined cut-off points. This means that the number of questions that need to be posed for each individual pair to be classified as a truth-telling pair cannot be predicted and determined on the basis of this study. In real-life, investigators would need this information.

In Vernham, Vrij, Mann, Leal and Hillman (2014), 24 real (truth-telling) and 22 pretend (lying) couples were interviewed in their pairs with the task of convincing an interviewer that they were a bona fide couple. Truth-telling couples were actually in a 
relationship for at least one year and were now living together. Lying couples were friends who had never been in a relationship or lived together. The study implemented a forced turntaking technique as a way of imposing cognitive load (see Vrij, Fisher, Mann \& Leal, 2006; Vrij, Granhag, Mann \& Leal, 2011; Vrij et al., 2008 for articles on the benefits of imposing cognitive load to detect deceit). The turn-taking technique involves the interviewer stating which of the two interviewees is to answer the question and then intervening every 20 seconds by stopping whichever of the interviewees is responding and asking the other interviewee in the pair to continue from the point at which their partner was stopped. It was found that when forced turn-taking was employed, truth-telling pairs were significantly more able to continue on from one another, whereas lying pairs were significantly more likely to wait and repeat what their partner last said before continuing. In a subsequent lie detection study laypersons were informed about these three turn-taking cues (continuations, repetitions, waiting), and it improved their ability to accurately detect deceit considerably (accuracy rates ranged from $79 \%-92 \%$ for truth-tellers and 73\%-86\% for liars across all three variables when observers who read the transcripts of these interviews were asked to pay attention to these cues). These accuracy rates obtained are amongst the highest obtained in verbal lie detection research.

Vernham, Vrij, Leal et al. (2014) used the same data-set as Vernham, Vrij, Mann et al. (2014), but examined how couples share cognition and 'think together' when discussing their relationship, a previous memorable day they had together, and a recent holiday they went on together. Therefore, the variables measured in this study aimed to reflect the fact that truthtelling couples should have a transactive memory system, whereas lying couples should not. The main findings were that truth-telling couples posed questions to one another, provided cues to one another (e.g., one pair member saying; "We watched something but I can't remember the name of it now", and the other pair member responding with; "The thing we 
were watching was a soap called Chalkhill Lives", which results in the first pair member replying; "Oh yeah, I remember now”), handed over remembering responsibility (e.g., one pair member saying to their partner; "You remember this better than me, why don't you explain it") and finished each other's sentences significantly more than lying pairs. Finishing each other's sentences in particular was a diagnostic cue to veracity with $83 \%$ of truth-tellers and $91 \%$ of liars being correctly classified based on the group means. Support was obtained for the theory of transactive memory.

The studies by Vernham, Vrij, Mann et al. (2014) and Vernham, Vrij, Leal et al. (2014) show the potential of a collective interviewing approach in the detection of sham marriages and illegal immigration, which is high up on the political agenda in various countries. However, it is important to acknowledge that truth-telling pairs always told a story about their real romantic relationship, whereas lying pairs always told a false story about a fictitious romantic relationship. This means that not only did veracity differ between the two conditions, but so did relationship status. Consequently, it could be argued that the findings obtained were due to truth-telling pairs having more experience of communicating shared events with one another than the lying pairs. However, the relationship length of the truthtelling pairs and the friendship length and closeness of the lying pairs were not associated with the occurrence of any of the dependent variables. Hence, it would seem that it was veracity that influenced the emergence of each of the cues (see Table 1).

Finally, in Nahari and Vrij (2014), 25 truth-telling pairs completed non-criminal activities together, whereas 25 lying pairs were separated so that one liar did the non-criminal activities alone and the other liar completed a criminal task alone. All pairs then had to convince an investigator that they had both completed the non-criminal activities together by typing up a collective statement. The verifiability approach (Nahari, Vrij \& Fisher, 2014) to lie detection was applied and it was found that truth-telling pairs, in comparison to lying pairs, 
provided significantly more details that could be verified to demonstrate they had completed activities together (e.g., "We went in the central library and asked a librarian where we could find the book we wanted"). Based on group means regarding this cue, $80 \%$ of truth-tellers and $96 \%$ of liars could be correctly classified. Whilst the verifiability approach has been shown to significantly differentiate truth-tellers from liars, this approach cannot be applied to historical cases or cases whereby innocent people cannot provide verifiable details. Nevertheless, the latter is increasingly unlikely to be an issue because nowadays a person's location can be traced by their mobile phone, social networking accounts, etc.

It is important to note that all seven collective interviewing studies conducted to date have involved dyads. However, research into collective interviewing is still in the very early stages and therefore smaller groups (i.e. pairs) are a good starting point for demonstrating the benefit of a collective approach in the detection of deception. Additionally, the most common number of individuals involved in a co-offending group has been found to be two (Hodgson \& Costello, 2006), and therefore an understanding of the deceit occurring within pairs and how to detect it is particularly applicable to the real world. Nevertheless, future studies should consider the effects of interviewing larger groups collectively on the emergence of cues to deceit.

To summarise, despite the minor procedural issues with each of the collective interviewing studies, they do all demonstrate the clear potential for using collective interviewing to detect deceit. The cues found to distinguish truth-tellers from liars (see Table 1) cannot be measured when individuals are interviewed separately. All the collective interviewing studies conducted support collective memory and the notion that collaboration can aid recall. Consequently, there is the potential for collective interviewing to actually enhance memory recall from truth-telling groups, but not from lying groups. 


\section{Individual vs. Collective interviewing}

To date, no study that has explored collective interviewing has implemented an individual interviewing condition (i.e. interviewing group members separately) as a comparison group, so the merits of a collective approach compared to an individual approach are unknown. However, what is clear from the studies conducted so far is that collective interviewing has considerable potential. First, unlike individual interviewing which can only focus on the individual indicators of deceit, collective interviewing can explore individual and social indicators of deceit. In other words, collective interviewing can focus on more cues than individual interviewing which means that, potentially, more cues to deceit could emerge. Second, when members of groups are interviewed separately, cues to deceit only emerge when unanticipated interview questions are asked during the interview because this negates any pre-planning of what to say during the interview (Vrij et al., 2009). When interviewing collectively, however, cues to deceit emerge from both anticipated and unanticipated interview questions (e.g. Vernham, Vrij, Leal, et al., 2014) because the focus is not on what is being said but on how the group members are communicating and interacting with one another. Third, a collective interviewing approach has strong theoretical support, ranging from cognitive (memory) to social (group) theory. If our knowledge about what is going on in the minds of truthful and deceptive individuals during collective interviews increases, then there is more possibility that researchers will be able to design interventions that exploit these different mind-sets of truth-tellers and liars, which may elicit new, or enhance existing, cues to deceit (Vrij \& Granhag, 2012). Finally, in some contexts, such as immigration interviews or alibi witness scenarios, it would be more timely and convenient to interview group members together at the same time.

Despite the clear potential of collective interviewing, there are also some limitations, especially when we consider memory and the effects of recalling information together. For 
example, human memory is susceptible to misinformation from a variety of sources, particularly other people (Loftus, 2005) and consequently collective interviewing may lead to memory contamination whereby one group member causes other group members to remember information incorrectly (Gabbert, Memon \& Allan, 2003). Additionally, whilst studies tend to show that collaborative groups (group members recalling information together) recall significantly more information than individuals (each group member recalling information alone), the studies show that nominal groups (pooled individuals whereby the group members recall information individually, but details are summed so that any duplicate details are removed) recall significantly more information than collaborative groups due to collaborative inhibition (the effect that occurs when a group of people working together remember and recall more than any one individual but recall less than their predicted potential) (Basden, Basden, Bryner \& Thomas, 1997, Weldon \& Bellinger, 1997). This collaborative inhibition is believed to be a result of retrieval disruption (e.g., each individuals' organisation of the material is interrupted by the way the other group members recall the information) and retrieval inhibition (e.g., other peoples non-cue words supress memory representations making them unavailable to retrieve) (Barber, Harris \& Rajaram, 2014). Although this collaborative inhibition needs to be considered when interviewing collectively, it is important to remember that group collaboration can also aid memory and therefore diminish any effects of collaborative inhibition (e.g., re-exposure, cross-cueing, and error-pruning).

Although it would seem that an understanding of group deceit through collective interviewing has benefits for practice, it is important to note that we do not think that collective interviewing should replace individual interviewing. Instead, we think that collective interviewing can be employed as an additional approach to individual interviewing. For example, the collective interview could be used in isolation whereby if the group raises suspicion in a collective interview, investigators could take the required actions they would 
normally take after interviewing individuals who raise suspicion (e.g., calling for assistance, collecting further evidence). Moreover, collective interviewing could act as an initial screening process to determine whether suspects then need to be interviewed individually. The opposite route could also be employed: If individual interviews with group members raise suspicion, they then could be interviewed collectively. Future research should determine not only when a combination of individual and collective interviewing is desirable, but should also examine the most efficient sequence in which collective and individual interviewing should be conducted (i.e. should the collective interview or the individual interview be conducted first? Or is this dependent on the context in which it is being applied?).

\section{Future research into collective interviewing: Group dynamics}

There are a number of promising future research opportunities within the area of collective interviewing to detect deceit. For this, it is important to discuss the theory behind group dynamics and how this could aid the understanding of how to detect deceit within groups. When applying a collective approach to the detection of deception, the group dynamics and how each of the group members bond and work together (labelled group formation; Arrow et al., 2000) are imperative for the group to succeed. Groups often form a structure with each member having a different role and being of a different status. Roles facilitate group functioning, and when these roles are inflexible or clouded, this can be detrimental to the group (Gersick \& Hackman, 1990). As discussed previously, detecting deception studies that have involved interviewing groups together demonstrate the importance of interaction and communication cues. Group roles influence how group members behave and communicate with one another; thus these roles are likely to influence the interaction and communication cues that arise from within that group.

Group roles are not equal and therefore individuals of a higher status (i.e. leaders who are deemed to be more knowledgeable and able to initiate the ideas and activities adopted by 
the group) will be more valued and respected than individuals who are of a lower or equal status (Chemers, 2001; Hollander, 1985). For example, individuals are typically reluctant to express disagreement with their group leaders in a group discussion, but are more willing to express disagreement with those group members who are not superior to themselves (Chemers, 2001; Hollander, 1985). In group discussions this could result in a systematic pattern of agreeing and disagreeing with fellow group members. If this is then examined within a collective interviewing context to detect deceit, 'agreement' and 'disagreement' could be measured as a function of the role or status within the group. As was previously mentioned in the memory processes section, lying group members tend to disagree less with each other, than truth-telling group members, as they believe that disagreements will come across as suspicious. It is therefore expected that low status individuals within a truth-telling group and low status individuals within a lying group will not differ from one another as both will tend to agree with the other group members. However, they will do this for different reasons: Liars will not disagree because they think this will put them under suspicion, whereas truth-tellers know their role within the group so will not disagree with higher status group members. Conversely, it is expected that high status truth-tellers and high status liars will differ from one another. That is, high status individuals within a truth-telling group will not be scared to disagree with other group members, whereas high status individuals within a lying group will not disagree with other group members through fear that this will look suspicious. Consequently, communication cues in the form of agreements and disagreements should theoretically differ depending on the veracity of the group when group members differ in status.

Aside from group status, the degree of dependence upon a group could potentially influence the outcomes. For example, individualistic cultures, such as Australia, New Zealand, Western Europe and the USA, are independent cultures with self-reliance being 
greatly emphasised. Individuals of such cultures focus on identifying more with the self so that their own needs are satisfied before those of the group. Conversely, collectivistic cultures, such as India, Japan and Korea, are interdependent cultures so that the well-being of each individual is related to the success of the group. Emphasis is put on group loyalty and conformity, with the self-identity of each individual developing from the relationships and interconnectedness between all group members (Hofstede, 1980, 2001; Hui, 1988).

Participants in the collective interviewing studies mentioned in this review are primarily from the UK and USA, therefore of an individualistic culture. Someone could argue that findings from collective interviewing studies in a collectivistic culture may be stronger in terms of the behaviours they show for protecting the group because supporting the group is more important in such cultures, and therefore the focus of all groups members will be on preventing any lies from being unveiled. Thus, the communicative and interactive cues to deceit that emerge from groups supporting collectivism may be more prevalent and detectable compared to the communicative and interactive cues shown to be indicative of deceit in groups supporting individualism.

Another concept to consider is group cohesiveness, which explores the properties of a group that effectively bind them together to give the group a sense of solidarity (Festinger, 1950). One way of exploring this notion of cohesiveness during collective interviewing is to consider what would happen to the cohesiveness of the group if a group member "slips up" during the interview. One would expect there to be a veracity effect because if the group are concealing information, then the rest of the group may perceive this individual as behaving differently to the rest and not satisfying the group goals or standards. The group may see this as a threat to cohesiveness and therefore a threat to their group's credibility. Subsequently, they may respond in a way that restores the group cohesiveness. For example, they may start to support the individual who slipped up, or find a way of explaining the information that this 
individual has provided. In that way, the group restores solidarity and motivates all group members, including the individual who slipped up, to act on behalf of the group. This type of response may not arise in a group whose members are not concealing information, because non-concealing group members are likely to be less concerned about their group cohesiveness during the interview and may be more willing to correct or disagree with other group members.

To summarise, psychological theories associated with group dynamics have not yet been applied to deception and deception detection, therefore we can only speculate about the

effect of group dynamics on cues to deceit. However, we believe that group dynamics can be important in understanding communication in collective interviewing and may result in the elicitation of cues to deceit. Future collective interviewing studies should not only explore deception detection in terms of memory or group dynamics, but should also consider a combination of them both. A clearer understanding of memory and the social processes surrounding groups could enable the identification of diagnostic cues to deceit that emerge when two or more interviewees are interviewed simultaneously, and could aid in the development of interview protocols that elicit or enhance such cues.

\section{Additional future research ideas into collective interviewing}

In the previous section about group dynamics we mentioned numerous ideas for future research. We believe that more important studies are required to get a more complete picture of collective interviewing in relation to deception which fall outside the group dynamics domain. These ideas are discussed in this section. First, future studies should consider alternative contexts or scenarios in which collective interviewing could be applied, for example, insurance claims (e.g., couples making a fire insurance claim on their house), the use of an informant (e.g., police putting an informant within a group to secretly gather information), security equipment (e.g., using CCTV to spot interactive behaviours between 
group members indicative of those with malicious intent), and house to house enquiries (e.g., interviewing whole families together about a nearby crime that they may or may not have witnessed). The more contexts which demonstrate how collective interviewing can succeed in differentiating liars from truth-tellers, the more law enforcement and other agencies will believe in its utility and practical value.

Second, the collective interviewing studies conducted so far differed in that in some studies the pairs were informed that they were going to be interviewed collectively (e.g., Vernham, Vrij, Mann et al., 2014), whereas this was not the case in other studies (e.g., Vrij et al., 2012). In future experiments, it could be manipulated whether or not group members are informed of how they will be interviewed. We expect that informing groups of liars that they will be interviewed collectively will make them develop individual deceptive strategies that focus on the fabricated story and on how they should behave in order to appear convincing (e.g., sitting still, avoiding stuttering). It is interesting to examine whether it will occur to them to discuss how they should communicate and interact with each other (e.g., adding information to each other's stories, looking at one another), and whether they could do this in such a way that they appear as truth-tellers. Since the collective interviewing studies in which group members knew they were going to be interviewed together (e.g., Vernham, Vrij, Mann, et al., 2014) resulted in similar cues to deceit as those obtained in other collective interviewing studies whereby group members did not know they were going to be interviewed together (e.g., Vrij et al., 2012), we expect communication cues to deception to also occur if groups know that they will be interviewed together.

Third, deception studies with individuals have shown that methods to elicit additional information, such as requesting someone to report the event in reverse order or using a model statement of a detailed answer, encourages truth-tellers more than liars to provide plausible additional information (Leal, Vrij, Warmelink, Vernham \& Fisher, 2015; Vrij, 2015; Vrij, et 
al., in press). Truth-tellers almost never report all they know in an initial free recall so there is plenty of opportunity for them to elaborate when methods to elicit additional information are implemented (Vrij, Hope \& Fisher, 2014). In contrast, liars prepare answers to questions and are more likely to report all they have prepared during the initial free recall (e.g., Shaw, Vrij, Mann, Leal \& Hillman, 2013; Warmelink, Vrij, Mann, Jundi \& Granhag, 2012), and therefore cannot elaborate when additional questions are asked. Furthermore, liars may lack the imagination to report more details or may be reluctant to report more details through fear that they will give away possible leads to investigators (Vrij, 2015; Vrij et al., in press). Someone could argue that the techniques encouraging interviewees to say more will be even more effective in eliciting cues to deceit in collective interviews than in individual interviews, because truth-telling groups could use various shared memory processes (as discussed above) to come up with the additional information.

\section{Conclusion}

The current review demonstrates that collective interviewing, whereby two or more people are interviewed together at the same time, has potential for detecting deceit. Studies have demonstrated that a collective interviewing approach allows for cues to deceit to emerge that cannot emerge when interviewing individuals, e.g., communicative and interactive cues, such as posing questions to one another, correcting and interrupting one another, and looking at each other. To improve our understanding of the deception occurring within groups and to facilitate lie detection in such groups, future studies need to enhance our understanding of memory and group dynamic theories in collective interviews and to apply this understanding to deception. 


\section{References}

Arrow, H., McGrath, J.E., \& Berdahl, J.L. (2000). Small groups as complex systems: Formation, coordination, development, and adaptation. Thousand Oaks, CA: Sage.

Barber, S.J., Harris, C.B., \& Rajaram, S. (2014). Why two heads apart are better than two heads together: Multiple mechanisms underlie the collaborative inhibition effect in memory. Journal of Experimental Psychology: Learning, Memory and Cognition, 41, 559-566. DOI: 10.1037/xlm0000037.

Barnier, A.J., \& Sutton, J. (2008). From individual to collective memory: Theoretical and empirical perspectives. Memory, 16, 177-182. DOI: 10.1080/09541440701828274.

Bartlett, F.C. (1932). Remembering: A study in experimental and social psychology. Cambridge: Cambridge University Press.

Basden, B.H., Basden, D.R., Bryner, S., \& Thomas III, R.L. (1997). A comparison of group and individual remembering: Does group participation disrupt retrieval? Journal of Experimental Psychology: Learning, Memory and Cognition, 23, 11761191. DOI: $10.1037 / 0278-7393.23 .5 .1176$.

Blumen, H.M., \& Stern, Y. (2011). Short-term and long-terms collaboration benefits on individual recall in younger and older adults. Memory \& Cognition, 39, 147-154. DOI: $10.3758 / \mathrm{s} 13421-010-0023-6$.

Bond, C.F., \& DePaulo, B.M. (2006). Accuracy of deception judgements. Personality and Social Psychology Review, 10, 214-234. DOI: 10.1207/s15327957pspr1003_2.

Chemers, M.M. (2001). Leadership effectiveness: An integrative review. In M.A. Hogg \& R.S. Tindale (Eds.), Blackwell handbook of social psychology: Group processes (pp. 376-399). Oxford, UK: Blackwell. 
DePaulo, B.M., Lindsay, J. L., Malone, B. E., Muhlenbruck, L., Charlton, K., \& Cooper, H. (2003). Cues to deception. Psychological Bulletin, 129, 74-118. DOI: 10.1037/00332909.129.1.74.

Driskell, J.E., Salas, E., \& Driskell, T. (2012). Social indicators of deception. Human Factors: The Journal of the Human Factors and Ergonomics Society, 54, 577-588. DOI: $10.1177 / 0018720812446338$.

Festinger, L. (1950). Informal social communication. Psychological Review, 57, 271282. DOI: $10.1037 / \mathrm{h} 0056932$.

Gabbert, F., Memon, A., \& Allan, K. (2003). Memory conformity: Can eyewitnesses influence each other's memories for an event? Applied Cognitive Psychology, 17, 533543. DOI: $10.1002 / \mathrm{acp} .885$.

Gersick, C.J., \& Hackman, J.R. (1990). Habitual routines in task performing groups. Organizational Behavior and Human Decision Processes, 47, 65-97. DOI: 10.1016/0749-5978(90)90047-D.

Gilovich, T., Savitsky, K., \& Medvec, V.H. (1998). The illusion of transparency: Biased assessments of others' ability to read one's emotional states. Journal of Personality and Social Psychology, 75, 332-346. DOI: 10.1016/S00221031(03)00056-8.

Granhag, P.A., \& Hartwig, M. (2015). The Strategic Use of Evidence (SUE) technique: A conceptual overview. In P.A. Granhag, A. Vrij, \& B. Verchuere (Eds.), Deception detection: Current challenges and new approaches. Chichester, England: Wiley.

Granhag, P.A., \& Strömwall, L.A. (1999). Repeated interrogations: Stretching the deception detection paradigm. Expert Evidence, 7, 163-174. DOI: 10.1023/A:1008993326434. 
Granhag, P.A., Strömwall, L.A., \& Jonsson, A.C. (2003). Partners in crime: How liars in collusion betray themselves. Journal of Applied Social Psychology, 33, 848-868. DOI: 10.1111/j.1559-1816.2003.tb01928.x.

Halbwachs, M. (1992). On collective memory. Chicago: University of Chicago Press.

Hartwig, M., Granhag, P.A., \& Luke, T. (2014). Strategic use of evidence during investigative interviews: The state of the science. In D.C. Raskin, C.R. Honts, \& J.C. Kircher (Eds.), Credibility Assessment: Scientific Research and Applications (pp. 1-36). Academic Press.

Hintz, V.B. (1990). Cognitive and consensus processes in group recognition memory performance. Journal of Personality and Social Psychology, 59, 705-718. DOI: 10.1037/0022-3514.59.4.705.

Hirst, W., \& Rajaram, S. (2014). Towards a social turn in memory: An introduction to a special issue on social memory. Journal of Applied Research in Memory and Cognition, 3, 239-243. DOI: 10.1016/j.jarmac.2014.10.001

Hodgson, B., \& Costello, A. (2006). The prognostic significance of burglary in company. European Journal of Criminology, 3, 115-119. DOI: 10.1177/1477370806059083.

Hofstede, G.H. (1980). Culture's consequences: International differences in work related values. Beverly Hills, CA: Sage.

Hofstede, G.H. (2001). Culture's consequences: Comparing values, behaviours, institutions and organizations across nations. Thousands Oak, CA: Sage.

Hollander, E.P. (1985). Leadership and power. In G. Lindzey \& E. Aronson (Eds.), Handbook of social psychology ( $3^{\text {rd }}$ Ed., Vol. 2, pp. 485-537). New York: Random House.

Hollingshead, A.B. (1998). Retrieval processes in transactive memory systems. Journal of Personality and Social Psychology, 74, 659-671. DOI: 10.1037/0022-3514.74.3.659. 
Hollingshead, A.B., \& Brandon, D.P. (2003). Potential benefits of communication in transactive memory systems. Human Communication Research, 29, 607-615. DOI: 10.1111/j.1468-2958.2003.tb00859.x.

Home Office. (2013). Sham marriages and civil partnerships: Background information and proposed referral and investigation scheme. Retrieved from: https://www.gov.uk/government/uploads/system/uploads/attachment_data/file/256257/ Sham_Marriage_and_Civil_Partnerships.pdf.

Hui, C.H. (1988). Measurement of individualism-collectivism. Journal of Research in Personality, 22, 17-36. DOI: 10.1016/0092-6566(88)90022-0.

Jundi, S., Vrij, A., Hope, L., Mann, S., \& Hillman, J. (2013). Establishing evidence through undercover and collective intelligence interviewing. Psychology, Public Policy, and Law, 19, 297-306. DOI: 10.1037/a0033571.

Jundi, S., Vrij, A., Mann, S., Hope, L., Hillman, J., Warmelink, L., \& Gahr, E. (2013). Who should I look at? Eye contact during collective interviewing as a cue to deceit. Psychology, Crime \& Law, 19, 661-671. DOI: 10.1080/1068316X.2013.793332.

Kassin, S.M., \& Gudjonsson, G.H. (2004). The psychology of confessions: A review of the literature and issues. Psychological Science in the Public Interest, 5, 33-44. DOI: 10.1111/j.1529-1006.2004.00016.x.

Leal, S., Vrij, A., Warmelink, L., Vernham, Z., \& Fisher, R. (2015). You cannot hide your telephone lies: Providing a model statement as an aid to detect deception in insurance telephone calls. Legal and Criminological Psychology, 20, 129-146. DOI: $10.1111 /$ lcrp.12017.

Loftus, E.F. (2005). Planting misinformation in the human mind: A 30-year investigation of the malleability of memory. Learning and Memory, 12, 361-366. DOI: $10.1101 / 1 \mathrm{~m} .94705$. 
McGloin, J.M., \& Piquero, A.R. (2009). 'I wasn't alone': Collective behaviour and violent delinquency. Australian \& New Zealand Journal of Criminology, 42, 336-353. DOI: 10.1375/acri.42.3.336.

Nahari, G., \& Vrij, A. (2014). Can I borrow your alibi? The applicability of the verifiability approach to the case of an alibi witness. Journal of Applied Research in Memory and Cognition, 3, 89-94. DOI: 10.1016/j.jarmac.2014.04.005.

Nahari, G., Vrij, A., \& Fisher, R.P. (2014). Exploiting liars' verbal strategies by examining the verifiability of details. Legal and Criminological Psychology, 19, 227-239. DOI: 10.1111/j.2044-8333.2012.02069.x.

Pociask, S., \& Rajaram, S. (2014). The effects of collaborative practice on statistical problem solving: Benefits and boundaries. Journal of Applied Research in Memory and Cognition, 3, 252-260. DOI: 10.1016/j.jarmac.2014.06.005.

Rajaram, S. (2011). Collaboration both hurts and helps memory: A cognitive perspective. Current Directions in Psychological Science, 000, 1-6. DOI: $10.1177 / 0963721411403251$.

Rogers-Millar, E.L., \& Millar, F.E. (1979). Domineeringness and dominance: A transactional view. Human Communication Research, 5, 238-246. DOI: 10.1111/j.1468-2958.1979.tb00637.x.

Ross, M., Blatz, C.W., \& Schryer, E. (2008). Social memory processes. In H.L. Roediger (Eds.), Learning and memory - A comprehensive reference, Vol. 2: Cognitive psychology of learning (pp. 911-926). New York, NY: Elsevier.

Shaw, D.J., Vrij, A., Mann, S., Leal, S., \& Hillman, J. (2013). Expect the unexpected? Variations in question type elicit cues to deception in joint interviewer contexts. Applied Cognitive Psychology, 27, 336-343. DOI: 10.1002/acp.2911. 
Soufan, A.H. (2011). The black banners: The inside story of $9 / 11$ and the war against alQaeda. New York: W. W. Norton \& Company.

Sporer, S.L., \& Schwandt, B. (2006). Paraverbal indicators of deception: A meta-analytic synthesis. Applied Cognitive Psychology, 20, 421-446. DOI: 10.1002/acp.1190.

Strömwall, L.A., Granhag, P.A., \& Jonsson, A.C. (2003). Deception among pairs: "Let's say we had lunch and hope they will swallow it!” Psychology, Crime \& Law, 9, 109-124. DOI: $10.1080 / 1068316031000116238$.

Van Mastrigt, S.B., \& Farrington, D.P. (2009). Co-offending, age, gender and crime type: Implications for criminal justice policy. British Journal of Criminology, 49, 552-573. DOI: $10.1093 / \mathrm{bjc} / \mathrm{azp} 021$.

Vernham, Z., Vrij, A., Leal, S., Mann, S., \& Hillman, J. (2014). Collective interviewing: A transactive memory approach towards identifying signs of truthfulness. Journal of Applied Research in Memory and Cognition, 3, 12-20. DOI: 10.1016/j.jarmac.2014.01.001.

Vernham, Z., Vrij, A., Mann, S., Leal, S., \& Hillman, J. (2014). Collective interviewing: Eliciting cues to deceit using a turn-taking approach. Psychology, Public Policy and Law, 20, 309-324. DOI: 10.1037/law0000015.

Verschuere, B., Ben-Shakhar, G., \& Meijer, E. (2011). Memory detection: Theory and application of the concealed information test. Cambridge, England: Cambridge University Press.

Vrij, A. (2008a). Detecting lies and deceit: Pitfalls and opportunities ( $2^{\text {nd }}$ Ed.). Chichester: John Wiley \& Sons.

Vrij, A. (2008b). Nonverbal dominance versus verbal accuracy in lie detection: A plea to change police practice. Criminal Justice and Behavior, 35, 1323-1336. 
Vrij, A. (2015). A cognitive approach to lie detection. In P.A. Granhag, A. Vrij, \& B. Verchuere (Eds.), Deception detection: Current challenges and new approaches. Chichester, England: Wiley.

Vrij, A., Fisher, R., Blank, H., Leal, S., \& Mann, S. (in press). A cognitive approach to elicit nonverbal and verbal cues of deceit. In J.W. van Prooijen \& P.A.M. van Lange (Eds.), Cheating, corruption, and concealment: The roots of dishonest behavior. Cambridge, England: Cambridge University Press.

Vrij, A., Fisher, R., Mann, S., \& Leal, S. (2006). Detecting deception by manipulating cognitive load. Trends in Cognitive Sciences, 10, 141-142. DOI:10.1016/j.tics.2006.02.003.

Vrij, A., \& Granhag, P.A. (2012). Eliciting cues to deception and truth: What matters are the questions asked. Journal of Applied Research in Memory and Cognition, 1, 110-117. DOI: 10.1016/j.jarmac.2012.02.004.

Vrij, A., Granhag, P.A., \& Porter, S. (2010). Pitfalls and opportunities in nonverbal and verbal lie detection. Psychological Science in the Public Interest, 11, 89-121. DOI: $10.1177 / 1529100610390861$.

Vrij, A., Granhag, P.A., Mann, S., \& Leal, S. (2011). Outsmarting the liars: Toward a cognitive lie detection approach. Current Directions in Psychological Science, 20, 2832. DOI: $10.1177 / 0963721410391245$.

Vrij, A., Hope, L., \& Fisher, R.P. (2014). Eliciting reliable information in investigative interviews. Policy Insights from Behavioral and Brain Sciences, 1, 129-136. DOI: $10.1177 / 2372732214548592$. 
Vrij, A., Jundi, S., Hope, L., Hillman, J., Gahr, E., Leal, S., Warmelink, L., Mann, S., Vernham, Z., \& Granhag, P.A. (2012). Collective interviewing of suspects. Journal of Applied Research in Memory and Cognition, 1, 41-44. DOI:

10.1016/j.jarmac.2011.12.002.

Vrij, A., Leal, S., Granhag, P.A., Mann, S., Fisher, R.P., Hillman, J., \& Sperry, K. (2009). Outsmarting the liars: The benefit of asking unanticipated questions. Law and Human Behavior, 33, 159-166. DOI: 10.1007/s10979-008-9143-y.

Vrij, A., Leal, S., Mann, S., Vernham, Z., \& Brankaert, F. (2015). Translating theory into practice: Evaluating a cognitive lie detection training workshop. Journal of Applied Research in Memory and Cognition. DOI:10.1016/j.jarmac.2015.02.002.

Vrij, A., Mann., S, Fisher, R.P., Leal., S., Milne, R., \& Bull., R. (2008). Increasing cognitive load to facilitate lie detection: The benefit of recalling an event in reverse order. Law and Human Behavior, 32, 253-265. DOI 10.1007/s10979-007-9103-y.

Vrij, A., Mann, S., Leal., S., \& Granhag, P.A. (2010). Getting into the minds of pairs of liars and truth-tellers: An examination of their strategies. The Open Criminology Journal, 3, 17-22. DOI: 10.2174/1874917801003010017.

Walczyk, J.J., Igou, F.P., Dixon, A.P., \& Tcholakian, T. (2013). Advancing lie detection by inducing cognitive load on liars: A review of relevant theories and techniques guided by lessons from polygraph-based approaches. Frontiers in Psychology, 4, 14. DOI: 10.3389/fpsyg.2013.00014.

Warmelink, L., Vrij, A., Mann, S., Jundi, S., \& Granhag, P. A. (2012). Have you been there before? The effect of experience and question expectedness on lying about intentions. Acta Psychologica, 141, 178-183. DOI: 10.1016/j.actpsy.2012.07.011. 
Wegner, D.M. (1987). Transactive memory: A contemporary analysis of the group mind. In B. Mullen \& G. R. Goethals (Eds.), Theories of group behaviour (pp. 185-208). New York: Springer-Verlag.

Wegner, D.M., Erber, R., \& Raymond, P. (1991). Transactive memory in close relationships. Journal of Personality and Social Psychology, 61, 923-929. Retrieved from: http://www.wjh.harvard.edu/ wegner/pdfs/Wegner,Erber,\&Raymond1991.pdf.

Wegner, D.M., Giuliano, T., \& Hertel, P.T. (1985). Cognitive interdependence in close relationships. In W.J. Ickes (Eds.), Compatible and Incompatible Relationships (pp. 253-276). New York: Springer-Verlag.

Weldon, M.S., \& Bellinger, K.D. (1997). Collective memory: collaborative and individual processes in remembering. Journal of Experimental Psychology: Learning, Memory and Cognition, 23, 1160-75. DOI: 10.1037//0278-7393.23.5.1160. 
Table 1

Overview of the collective interviewing studies completed so far and the deception cues measured when pairs are interviewed together at the same time.

\begin{tabular}{|c|c|c|c|c|c|c|}
\hline Collective interviewing study & & Truth-tellers & Liars & $F$ & $p$ & $d$ \\
\hline Deception cue & Context of study & Mean $(S D)$ & Mean $(S D)$ & & & \\
\hline Driskell, Salas \& Driskell (2012) & Brief investigative & & & & & \\
\hline Mutual eye gaze & interview & $9.88(8.70)$ & $3.77(3.75)$ & 5.39 & $.029 *$ & .91 \\
\hline Verbal transitions & & $7.19(4.79)$ & $.84(1.01)$ & 28.09 & $<.001 * * * *$ & .80 \\
\hline Posing questions & & $.64(.65)$ & $.25(.36)$ & 10.91 & $.003 * * *$ & .74 \\
\hline First person plural usage & & $3.52(1.94)$ & $3.18(1.91)$ & .44 & .513 & .18 \\
\hline Use of words related to social processes & & $12.51(4.90)$ & $10.20(2.12)$ & 2.96 & .098 & .61 \\
\hline Assent words & & $.77(.63)$ & $.27(.41)$ & 11.05 & $.003 * * *$ & .94 \\
\hline Vrij et al. (2012) & Time-consuming police- & & & & & \\
\hline Interruptions & style interview & $8.57(8.45)$ & $2.73(2.96)$ & 9.34 & $.004 * * *$ & .92 \\
\hline Corrections & & $1.48(1.75)$ & $.14(.35)$ & 12.39 & $.001 * * *$ & 1.06 \\
\hline Additional information & & $30.86(13.80)$ & $18.32(12.70)$ & 9.63 & $.003 * * *$ & .95 \\
\hline Jundi, Vrij, Mann, et al. (2013) & Time-consuming police- & & & & & \\
\hline Looking at each other & style interview & $3.74(1.57)$ & $3.00(1.41)$ & 4.11 & $.049 *$ & .62 \\
\hline Looking at the interviewer & & $4.26(1.18)$ & $5.18(1.10)$ & 6.61 & $.014 *$ & .77 \\
\hline
\end{tabular}


Jundi, Vrij, Hope, Mann \& Hillman (2013)

Posing questions when completing task

Vernham, Vrij, Mann, Leal \& Hillman (2014)

Number of swaps

Continuations per swap

Repetitions per swap

Waiting per swap

Vernham, Vrij, Leal, Mann \& Hillman (2014)

Posing questions to one another

Providing cues to one another

Handing over remembering responsibility

Finishing each other's sentences

\section{Nahari \& Vrij (2014)}

Verifiable details (prove pair together)
Intelligence timeline task

$$
\begin{array}{lllll}
10.68(5.97) & 5.48(4.00) & 12.22 & \mathbf{. 0 0 1} * * * & 1.04
\end{array}
$$

Immigration interview

$\begin{array}{lllll}8.83(8.00) & 9.05(5.78) & .010 & .919 & .03 \\ .70(.35) & .43(.19) & 10.419 & \mathbf{. 0 0 2} * * * * & .96 \\ .13(.14) & .52(.21) & 56.945 & <.001 * * * * & 2.19 \\ .33(.27) & .71(.24) & 24.818 & <.001 * * * * & 1.49\end{array}$

Immigration interview

$\begin{array}{lllll}15.83(10.62) & 9.41(5.80) & 6.319 & \mathbf{. 0 1 6 *} & .75 \\ 3.79(2.87) & .91(1.66) & 16.937 & <.001 * * * * & 1.23 \\ .63(.97) & .05(.21) & 7.513 & \mathbf{. 0 0 9 * *} & .83 \\ 5.92(2.95) & 1.14(1.46) & 47.217 & <.001 * * * * & 2.05\end{array}$

Alibi witness scenario

$* p<.05 ; * * p<.01 ; * * * p<.005 ; * * * * p<.001$ 